\title{
The Brain Neuropeptides and STAT3 Mediate the Inhibitory Effect of 17- $\beta$ Estradiol on Central Leptin Resistance in Young but Not Aged Female High-fat Diet Mice
}

\author{
Zeinab Farhadi \\ Shahid Sadoughi University of Medical Sciences and Health Services \\ Mohammad Khaksari (D mkhaksari@kmu.ac.ir) \\ Kerman University of Medical Sciences https://orcid.org/0000-0003-0770-4281 \\ Hossein Azizian \\ Shahid Sadoughi University of Medical Sciences and Health Services \\ Shahriar Dabiri \\ Kerman University of Medical Sciences
}

\section{Research Article}

Keywords: $17-\beta$ Estradiol, Leptin resistance, Aging, Neuropeptides, p-STAT3, High fat diet

Posted Date: August 11th, 2021

DOI: https://doi.org/10.21203/rs.3.rs-641717/v1

License: (c) (i) This work is licensed under a Creative Commons Attribution 4.0 International License. Read Full License

Version of Record: A version of this preprint was published at Metabolic Brain Disease on January 15th, 2022. See the published version at https://doi.org/10.1007/s11011-021-00884-4. 


\section{Abstract}

Aging and menopause effect on body composition and energy balance. Estrogen (E2) plays an important role in body's metabolism. The aim of the present study was to determine changes in leptin function in young intact and ovariectomized (OVX) animals in comparison to the aged animals treated with E2. Young (Intact and OVX 4 months) and aged (19-21 months) female mice were fed High fat diet (HFD) for 12 weeks and, then they were divided into eight groups including: Intact+OIL, Intact+E2, Intact+Pair body weight (PBW), OVX+OIL, OVX+E2, OVX+PBW, Aged+OIL, and Aged+E2. E2 was administered subcutaneously every four days for four weeks. Responsiveness to leptin was assessed by measuring energy balance components. Results showed that eating HFD increased weight and calorie consumption in young mice, and chronic treatment with E2 decreased both these variables in young animals. E2 only improved the sensitivity to leptin in young animals. Treatment with E2 resulted in increased a-MSH neuropeptide, reduced NPY and AgRP neuropeptides in the brain, and decreased serum leptin in the young animals. Also, treatment with E2 increased the expression of p-STAT3 molecular level in the hypothalamic arcuate nucleus (ARC) in the young animals. Our results indicated that response to E2 depended on age and E2 protects young HFD fed mice from obesity and improves leptin sensitivity.

\section{Introduction}

The growing trend of obesity has made it one of the biggest health challenges in the world, as it increases the risk of type II diabetes, cardiovascular disease, and some types of cancer (Wu et al., 2014). Leptin is a $16 \mathrm{kDa}$ polypeptide that is mainly secreted from fat tissue and plays an important role in controlling energy balance. The body's response to leptin includes increasing metabolism and decreasing food intake (Dardeno et al., 2010). Plasma leptin levels are higher in women than men, and this difference may be due to the stimulatory role of estrogen in the production of leptin (Rosenbaum et al., 1996). In women, the progression of diet-induced overweight is slower than in men, a difference that has been attributed to estrogen, and estrogen probably does this by increasing energy consumption and activity (Miller et al., 2012).

The strongest estrogen in females, 17- $\beta$ estradiol (E2), is known to reduce appetite (Farhadi et al., 2020). The effects of E2 are mainly mediated by two types of receptors, estrogen receptor a (ERa) and estrogen receptor $\beta(E R \beta)$. Studies show that lack of ERa isoform in hypothalamic pro-opiomelanocortin (POMC) neurons leads to overeating, so they conclude that ERa signaling plays a role in regulating food intake (Xu et al., 2011). As the major female sex hormone, E2 has lipolytic activity in women and reduces the production of lipids. This hormone also helps to regulate the leptin sensitivity (Miller et al., 2012).

The phenomenon of aging refers to a decrease in the function of body's physiological systems and is accompanied by a decrease in metabolic profile, changes in fat distribution, obesity and insulin resistance. All of these physiological changes are associated with age-related diseases and will eventually lead to increased mortality at old age (Kotz et al., 1999). The functional effects of leptin on the brain and peripheral organs will decrease with age. The redistribution in fat tissue and the increase in fat mass that occur in old and middle age are likely to contribute to increased plasma leptin levels, indicating that increasing plasma leptin levels in aging will not reduce leptin resistance (Carter et al., 2013). When comparing the effects of leptin resistance and metabolic disorders in aging, it seems that leptin resistance is the first factor involved in the development of metabolic disorders in aging (Carter et al., 2013). Studies show that despite the increase in plasma leptin levels in the elderly, there is a deficiency and weakness in leptin function compared to other age groups. According to this evidence, youth will be associated with leptin sensitivity and aging with increased leptin resistance, which is independent of the resistance caused by obesity or changes in fat distribution that can lead to metabolic syndrome caused by aging (Kotz et al., 1999). Aging also causes changes in body composition, such as changes in fat mass. The trend of aging will affect the size of fat mass, which includes an increase in the size of fat cells in middle-aged people and a decrease in the size of fat cells in the elderly compared to young people (Fernández-Agulló et al., 2001).

Menopause or aging of the female reproductive system is a natural and physiological process that occurs in the body and is referred to as natural aging. At the same time as menopause, the production of sex hormones (estrogen and progesterone) decreases rapidly, which can affect the functioning of central nervous system (Troen, 2003). With the onset of menopause and the changes that occur with age, the production of estrogen and its receptors will change, which can be associated with the emergence of age-related diseases such as leptin and insulin resistance and metabolic syndrome (Foster, 2012).

Page 2/21 
In general, obesity is the result of an imbalance between food intake, basal metabolism and energy expenditure. High fat diets causes weight gain and type II diabetes in different breeds of rats and mice. In both rats and mice, there is a positive correlation between fatty foods, weight gain and obesity. This type of obesity is known as dietary obesity (Sclafani and Springer, 1976).

Some changes in cellular processes, such as leptin signaling and the production of appetite-controlling neuropeptides, will be exacerbated in the presence of obesity, leading to leptin and insulin resistance as well as lack of regulation in energy homeostasis (Filippi and Lam, 2014). The phenomenon of fat redistribution that occurs during aging will disrupt the functional regulation of fat cells, which is associated with leptin resistance during aging (Carter et al., 2013).

Previous studies have shown that E2 reduces leptin resistance in ovariectomized young obese animals, rather than older animals (Litwak et al., 2014) and also it has been reported that menopause and aging are associated with an increased prevalence of obesity and metabolic disorders in women. One of the reasons for that can be contributed to the changes that take place in leptin signaling and the production of appetite-controlling neuropeptides that eventually lead to leptin resistance (Filippi and Lam, 2014). Thus, the aim of present study was to determine whether these changes in leptin function observed in young obese and ovariectomized animals (the model of menopause) in comparison to the old animals treated with E2, are due to changes in brain neuropeptides levels that control appetite. Also, to investigate other mechanisms such as changes in tyrosine-phosphorylated signal transducer and activator of transcription 3 (p-STAT3) signaling in response to leptin, and brain and plasma levels of leptin as an effective factor in different responses to E2 at different ages.

\section{Materials And Methods}

\section{Animals}

Young 4 months and aged 22 months female C57BL/6J mice were housed in a temperature and humidity-controlled animal house with a 12-h light/dark cycle and free access to food and water. Animals consumed High Fat Diet (HFD) in which 58.8\%, 27.5\%, and $14.7 \%$ of calories are from fat, carbohydrates, and proteins, respectively, a total caloric value of $\sim 5.9 \mathrm{kcal} / \mathrm{g}$, for 12 weeks. All experiments were performed in accordance with the ethical guidelines of the Kerman University of Medical Sciences Animal Ethics Committee (Permission No: 95/264 KA).

\section{Bilateral ovariectomy procedures}

Following anesthesia, a small incision was made in the abdomen in length. Skin, fascia and abdominal muscles were opened. Ovaries were appeared and removed. Then, 1-2 ml saline solution was poured in the abdomen and skins and muscles was stitched. In the sham surgery, similar incision was performed, but ovaries were not removed. Experiments started 2 weeks after ovariectomy (OVX) (Esmailidehaj et al., 2020).

\section{Drugs}

Ketamine and xylazine were purchased from Alfasan In., Utrecht, Netherlands. 17- $\beta$ estradiol (E2) and saline were obtained from Aburaihan Pharmaceutical (Tehran, Iran). Leptin and sesame oil were purchased from Sigma (St. Louis, MO, USA). E2 and leptin were dissolved in sesame oil and saline, respectively.

\section{E2 treatment}

At the end of 12 weeks of HFD feeding, animals received subcutaneous injection of E2 $(2 \mu \mathrm{g} / \mathrm{mice}$ in sesame oil; $100 \mu \mathrm{l})(\mathrm{Litwak}$ et

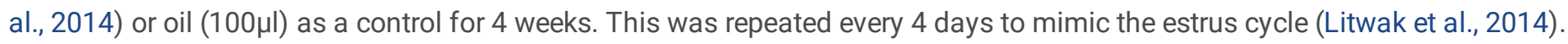

\section{Measurement of plasma leptin}

At the end of E2 therapy period, blood was sampled from the cardiac ventricle while the mice were under deep anesthesia. Plasma leptin was assayed by ELISA kit (Hangzhou, Eastbiopharm, China).

\section{Central leptin sensitivity test}


The central leptin sensitivity test was performed as follows. Mice were anesthetized by mixture of Ketamine/Xylazine and placed in stereotaxic device (USA, Illinois, Stoelting Co). An intracerebroventricular (icv) cannula was implanted into the lateral ventricle (-0.5 $\mathrm{mm}$ posterior, $1 \mathrm{~mm}$ lateral to bregma, and $1.5 \mathrm{~mm}$ below the surface of the skull, in accordance with Franklin and Paxinos [Paxinos and Franklin, 2001]). Seven days after implantation the mice were fasted for 6 hours, and either leptin $(1 \mu \mathrm{L}, 0.2 \mu \mathrm{g} / \mu \mathrm{L}$ : Sigma) (Litwak et al., 2014) or leptin's vehicle (saline) was injected into the lateral ventricle through the cannula. Body weight and energy intake were measured throughout the $48 \mathrm{~h}$ period following injection (Litwak et al., 2014).

\section{Measurement of brain leptin and Neuropeptides}

At the end of E2 therapy period, animals were sacrificed, and then the brains were quickly removed and immediately frozen in liquid nitrogen. The brains were weighed and homogenized in T-PER Tissue Protein Extraction Reagent with 0.5\% Triton X-100, 150 $\mathrm{mmol} / \mathrm{L} \mathrm{NaCl}, 50 \mathrm{mmol} / \mathrm{L}$ Tris, and a protease inhibitor cocktail (Pierce). Following homogenization, the samples were centrifuged $(4 \circ \mathrm{C}$ and $4000 \mathrm{~g}$ ) for $15 \mathrm{~min}$. The homogenate supernatant was collected. The protein content of the supernatant was estimated using a BCA Protein Assay Reagent Kit to ensure that an equal amount of protein from each sample was used for the assay. Brain leptin and neuropeptides including, Neuropeptide Y (NPY), a-Melanocyte-stimulating hormone (a-MSH), and Agouti-related protein (AgRP) were also determined using commercially available ELISA kits (Hangzhou, Eastbiopharm, China) according to the manufacturer's instructions.

\section{Immunohistochemical analysis}

For immunohistochemical staining, $2 \mu \mathrm{m}$ brain tissue sections were prepared from paraffin blocks and deparaffinized with xylene and hydrated by graded alcohols, washed by distilled water. Antigen retrieval was done by incubation with molar citrate buffer $1 \%$ $(\mathrm{pH}=6)$ in a microwave oven for $12 \mathrm{~min}$ and transferred to Phosphate Buffered Saline (PBS). To quench endogenous peroxidase activity, the sections were placed in $3 \%$ oxygen peroxide in methanol solution for 10 minutes. Then, sections were incubated with primary p-STAT3 antibody (1:1000 dilution; Cell Signaling Technology), for 60 minutes followed by they were then incubated with secondary antibody and washed by PBS. Before being counterstained with hematoxylin, slides were incubated with DAB chromogen. Finally, slides were dehydrated in $70 \%, 90 \%$ and $100 \%$ ethanol, cleared with xylene and mounted.

\section{Experiment 1}

Fig. 1 displays schematic representation of the experimental protocol. At the end of 12 weeks, to assess the effects of exogenous E2 on body weight and energy intake in young and aged animals that fed HFD, the animals were randomly assigned into six groups: 1) young intact E2-treated (Intact+E2), 2) young intact Oil-treated (Intact+OIL), 3) young OVX E2-treated (OVX+E2), 4) young OVX Oil-treated (OVX+OIL), 5) aged E2-treated (Aged+E2), and 6) aged Oil-treated (Aged+OIL) (Fig. 2).

\section{Experiment 2}

To assess whether E2 increases central sensitivity to leptin, or whether E2-induced weight loss is a factor in this increase, in addition to young E2-treated animals, a pair body weight (PBW) group was also designed. The PBW group included the Intact-PBW and OVXPBW, which received the oil-treatment but their diet was adjusted so that, their weight at the end of the study was similar to that of E2-treated animals (Litwak et al., 2014), and finally, their body weight, energy intake, brain neuropeptides (NPY, a-MSH, AgRP) and pSTAT3 were measured 48 hours after the injection of leptin (Litwak et al., 2014).

\section{Experiment 3}

At the end of the study, in order to assess the level of response to leptin in the presence of E2 and the changes in neuropeptides, leptin was administered to the animals of the first experiment and 48 hours later, their body weight, energy intake, brain neuropeptides (NPY, a-MSH, AgRP) and p-STAT3 were measured.

\section{Statistics}

Data were analyzed by two-way ANOVA repeated measurement for body weight change and energy intake over time followed by Bonferroni post hoc test. One-way ANOVA was used to analyze visceral, subcutaneous fat mass, ratio visceral/subcutaneous, and changes of body weight in Fig. 4. Other parameters were analyzed by two-way ANOVA, followed by Bonferroni multiple 
comparisons using GraphPad Prism 6.0 software (GraphPad Software, San Diego, CA, USA). Results are presented as mean \pm S.E.M and $P<0.05$ was considered statistically significant.

\section{Results}

\section{The effects of chronic E2 on the body weight in young and aged HFD mice}

Changes in body weight of animals in different study groups fed with HFD at the end of four weeks of E2 and oil injections are shown in table 1. E2 treatment in young intact animals and young OVX animals reduced body weight compared to the oil group $(P<0.001)$. However, this weight loss $(22 \%)$ in the young OVX group was more than the young intact group $(11 \%)(P<0.001)$. On the other hand, like the group treated with E2, the OVX+PBW group weighed less than the OVX+OIL group $(P<0.001)$, also body weight in this group was not significantly different from the E2 group. In older animals, unlike young animals, E2 treatment did not change body weight compared to the oil group.

Table 1. The effect of chronic administration (four weeks) of E2 or oil on body weight ( $\mathrm{g}$ ) in young (Intact or OVX) and aged HFD fed mice.

\begin{tabular}{|c|c|c|c|}
\hline $\begin{array}{l}\text { Treatment } \\
\text { Groups }\end{array}$ & OIL & E2 & PBW \\
\hline Young Intact & $28.11 \pm 0.4$ & $24.8 \pm 0.3 \S \S \S$ & $24.09 \pm 0.4$ \\
\hline Young OVX & $45.28 \pm 2.4$ & 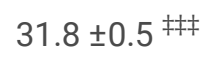 & 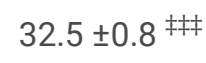 \\
\hline Aged & $28.3 \pm 1.2$ & $29.5 \pm 1$ & 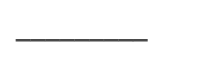 \\
\hline
\end{tabular}

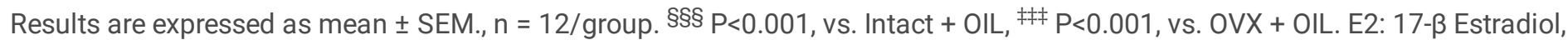
OVX: Ovariectomy, PBW: Pair body weight.

\section{The effects of chronic E2 on the energy intake in young and aged HFD mice}

Table 2 shows the daily energy intake in the various study groups fed with HFD at the end of four weeks of E2 and oil injections. E2 treatment in both intact and OVX young groups reduced the daily energy intake compared to the oil group $(P<0.001$, and $P<0.01$, respectively). The OVX+PBW group, like the group treated with E2, had lower daily energy intake than the OVX+OIL group $(P<0.001)$, also-the daily energy intake in this group was lower than the OVX+E2 group $(P<0.01)$. In older animals, unlike young animals, E2 treatment did not change the amount of daily energy intake compared to the oil group.

Table 2. The effect of chronic administration (four weeks) of E2 or oil on energy intake (kcal) in young (Intact or OVX) and aged HFD fed mice.

\begin{tabular}{|c|c|c|c|}
\hline $\begin{array}{l}\text { Treatment } \\
\text { Groups }\end{array}$ & OIL & E2 & PBW \\
\hline Young Intact & $14.3 \pm 0.4$ & $11.8 \pm 0.4$ §§§ & $11.68 \pm 0.2$ \\
\hline Young OVX & $14.75 \pm 0.3$ & $12.73 \pm 0.3$ 㧊 & $8.98 \pm 0.3_{\text {抹 †十 }}$ \\
\hline Aged & $10 \pm 0.4$ & $9.41 \pm 0.3$ & 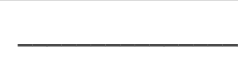 \\
\hline
\end{tabular}

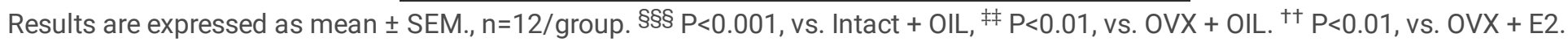
E2: $17-\beta$ estradiol, OVX: Ovariectomy, PBW: Pair body weight.

\section{The effects of chronic E2 on the leptin resistance in obese young and aged HFD mice}

In examining the hypothesis that states, E2 can inhibit leptin resistance in obese mice, the table 3 shows percent weight changes 48 hours after injection of leptin and saline in animals fed with HFD. Although central leptin injection resulted in a significant reduction 
in body weight in all young intact animals treated with E2, oil, and PBW animals compared to the saline group $(P<0.001)$, the percentage of weight loss in the Intact+E2 group was higher than the Intact+OIL group $(P<0.05)$, meaning that E2 had increased leptin sensitivity. On the other hand, there was no significant difference between E2 and PBW groups. Also, leptin injection resulted in weight loss only in the young OVX+E2 and OVX+PBW groups $(P<0.001)$, which means that there was a leptin resistance in the OVX+OIL group. In the OVX groups, such as the Intact group, weight loss was greater in the E2 group than in the oil group $(P<0.001)$, and E2 inhibited leptin resistance. Unlike intact animals, the percentage of weight loss in the OVX+E2 group was higher than the OVX+PBW group $(\mathrm{P}<0.001)$, which means that the reason for the decrease in leptin resistance in the OVX+E2 group was not due to weight gain inhibition, as E2 increased leptin sensitivity in the brain.

On the other hand, for aged animals, the results were similar to those of young intact animals, so that central leptin injection resulted in weight loss in both E2 and oil-treated groups $(P<0.001)$, and unlike to those of young intact mice, there was no significant difference between the two groups in that regard. This means that, leptin sensitivity was not eliminated in aged animals and this effect of leptin was not associated with E2.

Table 3. The effect of central leptin $(0.2 \mu \mathrm{g} / \mu \mathrm{l})$ injection on body weight change (\%) in HFD fed mice treated by E2 and oil during 48 $\mathrm{h}$ after a single injection of leptin compared with saline.

\begin{tabular}{|c|c|c|c|c|c|c|}
\hline & OIL & & E2 & & PBW & \\
\hline & Saline & Leptin & Saline & Leptin & Saline & Leptin \\
\hline Young Intact & $0.597 \% \pm 0.05$ & $-3.46 \% \pm 0.35 * * *$ & $0.8 \% \pm 0.16$ & 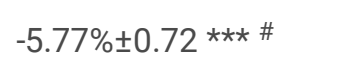 & $0.641 \% \pm 0.07$ & $-3.99 \% \pm 0.6 * \star *$ \\
\hline Young OVX & $-1.12 \% \pm 0.24$ & $-3.16 \% \pm .38$ & $-0.51 \% \pm 0.35$ & 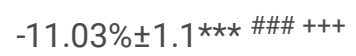 & $-0.88 \% \pm 0.27$ & $-5.12 \% \pm 0.51 * \star \star$ \\
\hline Aged & $-1.2 \% \pm 0.34$ & $-11.5 \% \pm 1.52 * \star \star \star$ & $-0.71 \% \pm 0.28$ & $-10.06 \% \pm 1.78 * \star \star$ & 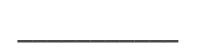 & 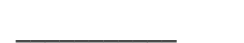 \\
\hline
\end{tabular}

Results are expressed as mean \pm SEM., $n=8$ /group. ${ }^{\star \star \star} P<0.001$, vs. own saline. ${ }^{\#} P<0.05$ and ${ }^{\# \#} P<0.001$, vs. Oil leptin. ${ }^{+++}$ $\mathrm{P}<0.001$, vs. PBW leptin. E2: 17- $\beta$ Estradiol, OVX: Ovariectomy, PBW: Pair body weight.

Table 4 shows the changes in energy intake 48 hours after leptin and saline injection in animals fed with HFD. Central leptin injection resulted in a significant reduction in energy intake in all of young intact animals treated with $E 2(P<0.01)$, oil and $P B W$ $(P<0.05)$ compared to the saline group. Also, leptin injections only reduced energy intake in the OVX+E2 $(P<0.001)$ and $O V X+P B W$ groups $(P<0.05)$, which means that there was leptin resistance in the oil group. In the OVX groups, the reduction in energy intake in the E2 group was less than in the oil group $(P<0.001)$, and E2 inhibited leptin resistance. Unlike intact animals, in OVX animals, the energy intake level in the E2 group was lower than the PBW group $(P<0.001)$, which means that the reason for the decrease in leptin resistance in the E2 group was due to increased leptin sensitivity in brain.

On the other hand, just like changes observed in weight loss of aged animals in response to leptin, the level of energy intake in aged animals was similar to that of intact animals, so that central leptin injection reduced energy intake in both Aged $+E 2(P<0.05)$ and Aged+OIL groups $(P<0.01)$, and there was no significant difference between the two groups, meaning that there was no leptin resistance in older animals.

Table 4. The effect of central leptin $(0.2 \mu \mathrm{g} / \mu \mathrm{l})$ on energy intake (kcal) in HFD fed mice treated by E2 and oil during $48 \mathrm{~h}$ after a single injection of leptin compared with saline.

\begin{tabular}{|c|c|c|c|c|c|c|}
\hline & \multicolumn{2}{|l|}{ OIL } & \multicolumn{2}{|l|}{ E2 } & \multicolumn{2}{|l|}{ PBW } \\
\hline & Saline & Leptin & Saline & Leptin & Saline & Leptin \\
\hline Young Intact & $14 \pm 0.2$ & $12.5 \pm 0.4$ * & $13.8 \pm 0.09$ & $12 \pm 0.2$ ** & $14 \pm 0.1$ & $12.6 \pm 0.2$ * \\
\hline Young OVX & $14.1 \pm 0.1$ & $13.7 \mid \pm 0.1$ & $13.1 \pm 0.2$ & 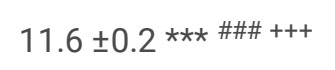 & $14.2 \pm 0.1$ & $13.3 \pm 0.1$ * \\
\hline Aged & $9.9 \pm 0.2$ & $8.1 \pm 0.3$ ** & $9.8 \pm 0.2$ & $7.5 \mathrm{kcal} \pm 0.4$ * & 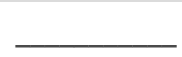 & 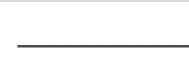 \\
\hline
\end{tabular}

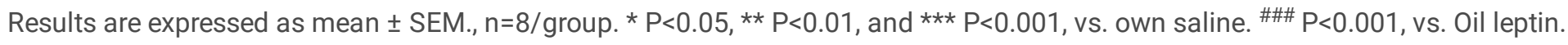
${ }^{+++} \mathrm{P}<0.001$, vs. PBW leptin. E2: 17- $\beta$ Estradiol, OVX: Ovariectomy, PBW: Pair body weight. 


\section{The effects of chronic E2 on brain NPY in young and aged HFD mice}

As seen in the Fig. 3A, leptin injection resulted in a reduction of brain NPY, in young intact mice fed with HFD, treated with E2 $(P<0.001)$ and PBW $(P<0.01)$ compared to the saline group. Also, the amount of this neuropeptide in $E 2$ group was less than the oil $(P<0.001)$ and PBW $(P<0.05)$ groups. Leptin injection, as in the young intact group, reduced brain NPY only in OVX+E2 and OVX+PBW groups $(P<0.001)$, and the amount of this neuropeptide in the OVX+E2 group was lower than in the OVX+OIL $(P<0.001)$ and OVX+PBW $(P<0.05)$ groups (Fig. 3B). This means that inhibiting effect of E2 on leptin resistance in HFD animals was not due to weight gain prevention, but was due to the central effect of E2. On the other hand, in aged animals, unlike young animals, leptin injection decreased brain NPY in both E2 $(P<0.001)$ and oil $(P<0.05)$ groups $(F i g .3 C)$, meaning that in older animals, unlike young animals, leptin resistance for inhibition of NPY level was not created and E2 had no effect on aged animals.

\section{The effects of chronic E2 on brain AgRP in young and aged HFD mice}

Leptin injection resulted in a reduction of brain AgRP, in young intact mice treated with E2 compared to the saline group $(P<0.001)$, and the amount of this peptide in the E2 group was lower than the oil and PBW groups $(P<0.001)$ (Fig. 4A). Also, as in the young intact group, leptin injection decreased brain AgRP only in the OVX+E2 group $(P<0.01)$, and the level of this index was lower in the E2 group than in the other two groups $(P<0.001)$ (Fig. 4B). This means that the decrease in this neuropeptide, like the decrease in NPY in the E2-treated group, was due to the central effects of E2 in reducing leptin resistance. In addition, in aged animals, as observed for NPY, leptin sensitivity for the reduction of this peptide was maintained, because central leptin injections reduced brain AgRP in both Aged+E2 $(P<0.001)$ and Aged+OIL $(P<0.01)$ groups, and E2 had no effect on aged animals unlike the young animals (Fig. 4C).

\section{The effects of chronic E2 on brain a-MSH in young and aged HFD mice}

In the Fig. 5A, central leptin injection resulted in an increase in a-MSH in young intact animals fed with HFD in the E2 and oil groups compared to the saline group $(P<0.01$, and $P<0.05$, respectively), and there was no significant difference between the two groups in that regard, which means that $\mathrm{E} 2$ had no effect on the increase of a-MSH in young intact animals. This is while leptin had no effect on the PBW group, despite the fact that the weights of the PBW and E2 groups were the same. Ovariectomy eliminated the effects of oil, so that leptin injection resulted in an increase in a-MSH only in the OVX+E2 group $(P<0.05)$, and the amount of this neuropeptide in the OVX+E2 group was higher than the OVX+OIL group $(\mathrm{P}<0.001)$ (Fig. 5B). This means that, unlike young intact animals, E2 increased sensitivity to leptin for a-MSH increments in young OVX animals. On the other hand, contrary to what was observed for the previous two neuropeptides, resistance to the leptin response was created in aged animals (Fig. C5), which means no significant difference was observed between leptin and saline, and also E2 had no effect.

\section{The effects of chronic E2 on serum leptin level in young and aged HFD mice}

The effects of E2 and oil injections on serum leptin level in different study groups fed with HFD are shown in Fig. 6. Serum leptin levels in young intact animals did not differ significantly between different groups, but serum leptin levels in OVX+OIL group were higher than $O V X+E 2$ and $O V X+P B W$ groups $(P<0.001)$. This could be due to higher weight of animals in the oil group compared with other two groups, which further prove that there was no significant difference between the PBW group treated with oil and E2 group in terms of serum leptin levels. Injection of E2 in older animals did not cause significant changes in serum leptin levels (Fig. 6), possibly due to their low weight, as a significant reduction in their weight was observed compared to the ovariectomized animals fed with oil $(P<0.001)$.

\section{The effects of chronic E2 on brain leptin level in young and aged HFD mice}

Brain leptin levels, similar to serum leptin levels, were higher in OVX young animals fed with HFD than in intact and aged animals $(P<0.001)$, although in OVX animals, no significant difference was observed between the E2, PBW and oil groups, meaning that E2 had no effect on reducing brain leptin. Similar to serum leptin level, E2 injection in aged animals did not have effect on brain leptin levels (Fig. 7).

Table 5 shows the Comparison of brain and serum levels of leptin in young intact, young OVX, and age animals after four weeks of E2 treatment. As can be seen in this table, serum leptin levels in all study groups are higher than brain leptin levels $(P<0.001)$, 
probably indicating the production of leptin in peripheral tissues such as fat tissue.

Table 5. Comparison of brain and serum leptin levels in young and aged animals

\begin{tabular}{|c|c|c|c|c|c|c|c|c|c|}
\hline $\begin{array}{l}\text { Groups } \\
\text { Paramet }\end{array}$ & Intact Oil & Age E2 & Intact E2 & $\begin{array}{l}\text { Intact } \\
\text { PBW }\end{array}$ & OVX Oil & OVX E2 & $\begin{array}{l}\text { OVX } \\
\text { PBW }\end{array}$ & Age Oil & Age E2 \\
\hline $\begin{array}{l}\text { Serum } \\
\text { Leptin } \\
\text { Level } \\
(\mathrm{ng} / \mathrm{ml})\end{array}$ & $165 \pm 3 * \star \star$ & $140 \pm 5^{\star \star \star}$ & $144 \pm 3^{\star \star *}$ & 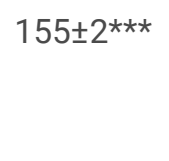 & $307 \pm 10 * \star \star$ & $205 \pm 6 * \star \star$ & $214 \pm 8^{\star \star *}$ & $126 \pm 9 * * *$ & $154 \pm 5^{\star \star \star}$ \\
\hline $\begin{array}{l}\text { Brain } \\
\text { Leptin } \\
\text { Level } \\
(\mathrm{ng} / \mathrm{ml})\end{array}$ & $75 \pm 3$ & $69 \pm 6$ & $60 \pm 5$ & $78 \pm 5$ & $145 \pm 2$ & $144 \pm 7$ & $130 \pm 3$ & $72 \pm 4$ & $69 \pm 6$ \\
\hline
\end{tabular}

Results are expressed as mean \pm SEM., $n=12$ /group. ${ }^{* \star *} \mathrm{P}<0.001$, vs. own brain. E2: $17-\beta$ Estradiol, OVX: Ovariectomy, PBW: Pair body weight, Intact: Young intact.

\section{The effects of chronic E2 on the molecular level of p-STAT3 in young and aged HFD mice}

In another part of this study, to confirm the activation of leptin signaling in arcuate (ARC) nucleus and changes in leptin resistance, the molecular level of p-STAT3 (a known marker for leptin function in ARC nuclei) was examined in different groups receiving HFD. As shown in Fig. 8, leptin injection in young intact animals resulted in increase the number of cells expressing p-STAT3 compared to the saline group. Also, injection of leptin in young animals treated with E2 increased the number of cells expressing p-STAT3 compared to the oil group. A similar effect was observed in OVX young animals, which means that an increase in p-STAT3 expression was observed after leptin injection in E2-treated animals. This means that E2 stimulated the signaling pathway of leptin in the ARC nucleus of the hypothalamus in young animals, thereby causing sensitivity or reduced resistance to leptin.

In addition, in the present study, for the first time we showed that injection of leptin in old animals fed with HFD receiving oil increased the number of cells that express p-STAT3. On the other hand, as shown in Fig. 8, E2 consumption did not alter p-STAT3 expression, confirming the lack of effect of E2 on weight as well as brain neuropeptides.

\section{Discussion}

Menopause and aging, which are associated with an increased prevalence of obesity and metabolic disorder in women, in part are due to changes in leptin signaling and the production of appetite-controlling neuropeptides, which eventually lead to leptin resistance (Foster, 2012). The aim of present study was to determine whether the observed changes in leptin function in menopause and aging among mice fed with HFD are due to the lack of female sex hormone (estrogen). The main findings of present study are: 1- Chronic consumption of E2 (four weeks) led to weight loss and energy expenditure in young animals without ovaries compared to older animals. 2- E2 in young animals increased the effects of leptin on weight loss and energy expenditure, although this effect on the reduction of leptin resistance was not observed in older animals. 3- Consumption of E2 in the presence of leptin only increased the neuropeptide of a-MSH in the young animals, and not the old ones, and decreased the neuropeptides of NPY and AgRP. 4- Consumption of E2 in the presence of leptin only increased the p-STAT3-positive cell number in the ARC nuclei of the young animals' hypothalamus and not the old ones. 5- Serum leptin levels were higher than brain leptin levels, and serum leptin levels were lower in E2 group in young animals.

In line with the present study, which showed that the weight of young animals without ovaries on a high-fat diet was higher than the young animals with ovaries, a positive relationship has been reported between the percentage of fat in the diet, weight gain and obesity in mice, and also the mice fed with HFD are more prone to fat deposits and obesity (Ludgero-Correia Jr et al., 2012). In addition, it has been reported that menopause in women and menopausal model in rodents directly cause fat accumulation and weight gain, and ovariectomy in animals on a high-fat diet exacerbates weight gain (Litwak et al., 2014). The possible mechanisms 
for this weight gain include decreased metabolism and increased visceral fat accumulation (Farhadi et al., 2020). On the other hand, unlike young animals without ovaries, no weight gain was observed in old animals fed with high-fat diet, although they consumed less energy than younger animals. It has been reported that obesity in mice increases until middle age and then begins to decrease, possibly due to decreased muscle mass (Lei et al., 2006), increased metabolism, and lack of increase in visceral and subcutaneous fat (Farhadi et al., 2020) compared to the OVX animals.

In another part of present study, it was shown that following chronic administration of E2, the weight of animals decreased in both young groups, which could probably be due to a decrease in calorie consumption. In this study we saw that, E2 decreased calorie consumption in both young groups treated with E2. In agreement with this study, it has been reported that estrogen reduces food intake by increasing anti-appetite messages and decreasing appetite messages (Argente-Arizón et al., 2017). In addition to the estrogen-induced reduction of food intake described above, other possible mechanisms for estrogen-induced weight loss include induction of fatty acid oxidation (Litwak et al., 2014), inhibition of the genes involved in lipogenesis, inhibiting inflammation in the hypothalamus, and the increase in ERa in ARC nuclei of OVX animals (Farhadi et al., 2020). However, unlike young animals, estrogen did not reduce weight in old animals, which is one of the possible reasons which could be due to the lack of reduction in energy consumption as observed in this study, although the mechanism, by which E2 does not increase ERa in the hypothalamus of old animals, has also been reported (Farhadi et al., 2020).

In the other part of this study, the response to leptin in young and old animals in the presence or absence of estrogen was investigated. Consumption of a high-fat diet caused leptin resistance only in young animals without ovaries and did not change the leptin response in old animals. Chronic treatment with E2 in these animals reduced leptin resistance despite consuming a high-fat diet. It is conceivable that estrogen may have decreased body weight and food intake in the same way. Consumption of high-fat foods in OVX animals has been reported to lead to leptin resistance (Matyšková et al., 2010), with normalization of leptin receptor expression in the brain after estradiol injection being possible causes of it (Kimura et al., 2002). Another possibility is the prevention of weight gain by estrogen, which was not confirmed in our study, because there was leptin resistance in young weigh-matched animals, despite their weight being similar to that of estrogen group. This finding refutes the hypothesis that states; no change in leptin sensitivity occurs by estrogen in old animals due to lack of weight gain in these animals (Balaskó et al., 2014). Other mechanisms to justify leptin action in old mice include lack of weight gain (Balaskó et al., 2014) and lack of leptin messaging in the brain (M Carrascosa et al., 2011).

Chronic estrogen therapy in our study increased brain levels of a-MSH (an appetite-suppressing neuropeptide in the brain) in young animals receiving leptin and this did not happen in old animals. Also in young groups, since leptin only increased a-MSH levels in estrogen-treated groups, it can be concluded that prevention of weight gain by estrogen could not be the cause of reduction in leptin resistance. In agreement with the present study, it has been reported that ovariectomy reduces POMC expression and a-MSH concentration in ARC nuclei, all of which are reversed by E2 therapy (Pelletier et al., 2007). E2 treatment in obese animals with leptin resistance also increases a-MSH production (Enriori et al., 2007). POMC neurons in ARC nuclei are probably the E2 target cells (Pelletier et al., 2007), because they increase excitatory synapses to POMC neurons (Gao et al., 2007). In addition, the effects of estrogen on these neurons and the reduction of food intake are mediated by ERa, because most estrogen-stimulated synapses to POMC neurons occur in proestrus (estrogen concentration is maximal) phase, and removal of ERa from POMC neurons causes overeating in mice (Mauvais-Jarvis et al., 2013). Since our results showed no effect of estrogen on the change of this neuropeptide in old animals, we can conclude that probably one of the reasons for the lack of estrogen effect on weight loss and reduced food intake in aged animals was the lack of increase in a-MSH.

NPY is an appetizing neuropeptides that is synthesized in the ARC nuclei of the hypothalamus and plays a role in regulating food intake and energy adjustment (Yokosuka et al., 1999). The results of our study showed that estrogen injection in young animals receiving leptin reduced brain NPY level, while it had no effect on old animals. In line with the present study, NPY has been reported to mediate overeating and reduce energy expenditure in endogenous estrogen-free animals, and its reduction in expression and release is probably a key mechanism by which, estrogen affects metabolism and food intake (Litwak et al., 2014). Estrogen therapy has also been reported to reduce NPY expression in OVX animals (Pelletier et al., 2007). However, it is not yet clear exactly how estrogen affects NPY gene expression or affects which neurons and in which area of the hypothalamus. In the present study, although in aged animals, this neuropeptide decreased in the presence of leptin, E2 had no effect on the amount of this neuropeptide. Studies have not come to a same conclusion about NPY in old age, because old age causes a reduction in the

Page 9/21 
expression of NPY gene, while in human, the NPY level increases with age (Wysokiński et al., 2015). The results of present study indicate that one of the possible mechanisms, by which E2 reduced appetite and weight, is an increase in a-MSH and a decrease in NPY in the brain.

Unlike the other two neuropeptides, less information is available on the role of estrogen on AgRP. The results of our study showed that estrogen injection reduced AgRP levels not only in young animals but also in older animals receiving leptin. In agreement with the present study, estrogen administration has been reported to suppress NPY and AgRP (Litwak et al., 2014), which slows down feeding responses in animals (Litwak et al., 2014). However, its reduction in older animals does not mean the reduction of leptin resistance in the presence of estrogen in these animals (Wysokiński et al., 2015). In aged mice, AgRP is severely reduced, and hunger-induced changes in AgRP gene expression are reduced in old age (Wolden-Hanson et al., 2004). However, so far no information is available on aging-related changes in human AgRP levels as well as the effects of estrogen on this neuropeptide. Based on present study, it appears that a decrease in this neuropeptide, like a decrease in NPY or an increase in a-MSH, is brain mediation for the anorectic effect of estrogen, although this does not explain the lack of E2 effect in old animals.

In another part of present study, we found that serum leptin level was higher in animals with higher body fat mass, so that these levels were lower in the estrogen-receiving and weight-matched groups. According to our study, leptin is secreted from adipose tissue and therefore, its serum level is directly related to body fat mass (Brown and Clegg, 2010). Also, an increase in circulating leptin level, which is associated with an increase in body fat in OVX mice and obesity in humans, leads to leptin resistance by decreasing its receptors (Münzberg et al., 2004). In agreement with our study that showed estrogen injections in OVX animals reduced circulating leptin level, Matyšková R et al. (Matyšková et al., 2010), found that estrogen injections reduced plasma leptin levels, and also in ArKo mice, whose aromatase gene was defective, in addition to weight gain, the amount of leptin was high. Since one of the causes of obesity has been reported to be an increase in central resistance to leptin (Ainslie et al., 2001), another possible mechanism of estrogen for restoration and maintenance of sensitivity to leptin in OVX mice is the normalization or reduction of plasma leptin levels and reduction of body fat mass in comparison to total body weight (Matyšková et al., 2010). Moreover, a possible reason for the lack of estrogen effect on plasma leptin level in old mice is their lack of weight gain during consumption of high-fat diet and the lack of E2 effect on their weight.

Comparing the serum level of leptin with its brain level, we found that in all study groups, serum level was higher than brain level. In agreement with the present study, it has been reported that the level of leptin in cerebrospinal fluid in obese people has been reduced, despite higher serum level of leptin in them, which is probably due to the disruption in leptin transfer from blood-brain barrier (Carter et al., 2013). On the other hand, it has been shown that there is a positive and direct relationship between leptin level in cerebrospinal fluid and BMI of individuals (Schwartz et al., 1996). It has also been reported that the ratio of cerebrospinal fluid leptin to serum is higher in lean individuals than in obese individuals (Schwartz et al., 1996). So far, very few studies have been conducted on the effects of estrogen on the entry of leptin into the brain, its transfer through the blood-brain barrier, and its exact mechanism of action.

Preliminary studies have shown that peripheral injection of leptin in mice fed with high-fat diet has resulted in the disruption of signaling pathway of leptin due to impaired binding of STAT3 to DNA and leptin resistance and reduced effects of leptin on weight loss occur (Münzberg et al., 2004). On the other hand, it has been reported that leptin sensitivity changes in women along with changes in sex hormones, and also high-fat food reduces estrogen levels in female mice (Litwak et al., 2014). Therefore, in the last part of present study, we examined leptin resistance in mice fed with high-fat diet treated with E2 through qualitative measurement of the p-STAT3 molecule expression in the ARC nucleus region. The results showed that E2 increased p-STAT3 in both young groups, but not in old animals. The results also showed that treatment of OVX animals with estrogen increased the level of P-STAT3 compared to the oil group. However, the level of P-STAT3 in aged animals receiving oil was higher than animals without ovaries receiving oil. In line with the present study, it has been reported that in male animals (no study has been done in old female animals), increasing age is associated with an increase in P-STAT3 (Hosoi et al., 2005), and weight loss has an effective role in increasing leptin sensitivity. However, a study, contrary to our study, showed that aging is associated with increased leptin resistance (Gabriely et al., 2002). One possible reason for this contradicting result could be due to differences in the species and age range of the animals. Overall, the results of this study showed that eating a HFD increased weight and calorie consumption in young mice, and chronic treatment with E2 decreased both these variables in young animals. Estrogen probably in young mice decreases leptin resistance caused by high-fat diet, as it has been observed that weight loss and reduced calorie consumption in

Page 10/21 
response to leptin increase in the presence of estrogen in these animals. One of the possible mechanisms of E2 for reducing the resistance in leptin response is to increase a-MSH neuropeptide and decrease NPY and AgRP neuropeptides in the brain. However, since estrogen did not alter these neuropeptides in old animals, it can be concluded that the same mechanism is the possible reason for the lack of estrogen effect on changing leptin resistance, weight change and calorie consumption in old mice. Another possible mechanism for increasing estrogen sensitivity to leptin is a decrease in plasma leptin levels in these young animals rather than older animals. It is also possible that E2, by increasing the P-STAT3 molecular level in the hypothalamic ARC nuclei, which was reduced in animals on high-fat diet, intensified leptin signaling pathway in this nuclei as another mechanism to reduce leptin resistance. We suggest future studies to investigate E2 target neurons for changing these neuropeptides, and also to examine the effect of estrogen on middle-aged animals. Also, genomic and non-genomic pathways of estrogen should also be studied in young and aged animals for inducing a decrease in leptin resistance.

\section{Abbreviations}

E2

17- $\beta$ estradiol

ERa Estrogen receptor a

ER $\beta \quad$ Estrogen receptor $\beta$

POMC Pro-opiomelanocortin

p-STAT3 Phosphorylated signal transducer and activator of transcription 3

HFD High fat diet

OVX Ovariectomized

ICV Intracerebroventricular

NPY Neuropeptide Y

a-MSH Alpha-melanocyte stimulating hormone

AgRP Agouti-related protein

PBS Phosphate-buffered saline

PBW Pair-body weight

Lep Leptin

Sal Saline

ARC Arcuate

\section{Declarations}

\section{Funding}

The present work was financially supported Iran National Science Foundation (INSF) under grant ID 94811516 to professor Mohammad Khaksari.

\section{Conflict of interest}

The authors declare that they have no conflict of interest.

Availability of data and material 
The data that support the findings of this study are available on request from the corresponding author, [initials]. The data are not publicly available due to [restrictions e.g. their containing information that could compromise the privacy of research participants].

\section{Code availability}

Not applicable

\section{Author contributions}

Farhadi Z performed the majority of experiments, analyzed the data, and drafted the manuscript. Khaksari $\mathrm{M}$ and Azizian $\mathrm{H}$ designed the research and provided critical revision of the manuscript for important intellectual content. Dabiri SH conducted the molecular biology assays and assisted in writing the manuscript. The authors declare that all data were generated in-house and that no paper mill was used.

\section{Ethical approval}

All animal experiments were performed in accordance with the ethical guidelines of the Kerman University of Medical Sciences Animal Ethics Committee (Permission No: 95/264 KA).

\section{Consent to participate}

Not applicable

\section{Consent for publication}

Not applicable

\section{References}

AINSLIE, D., MORRIS, M., WITTERT, G., TURNBULL, H., PROIETTO, J. \& THORBURN, A. 2001. Estrogen deficiency causes central leptin insensitivity and increased hypothalamic neuropeptide Y. International journal of obesity, 25, 1680-1688.

ARGENTE-ARIZóN, P., GUERRA-CANTERA, S., GARCIA-SEGURA, L. M., ARGENTE, J. \& CHOWEN, J. A. 2017. Glial cells and energy balance. J Mol Endocrinol, 58, R59-R71.

BALASKó, M., SOóS, S., SZEKELY, M. \& PETERVáRI, E. 2014. Leptin and aging: Review and questions with particular emphasis on its role in the central regulation of energy balance. Journal of chemical neuroanatomy, 61, 248-255.

BROWN, L. \& CLEGG, D. 2010. Central effects of estradiol in the regulation of food intake, body weight, and adiposity. The Journal of steroid biochemistry and molecular biology, 122, 65-73.

CARTER, S., CARON, A., RICHARD, D. \& PICARD, F. 2013. Role of leptin resistance in the development of obesity in older patients. Clinical interventions in aging, 8, 829.

DARDENO, T. A., CHOU, S. H., MOON, H.-S., CHAMBERLAND, J. P., FIORENZA, C. G. \& MANTZOROS, C. S. 2010. Leptin in human physiology and therapeutics. Frontiers in neuroendocrinology, 31, 377-393.

ENRIORI, P. J., EVANS, A. E., SINNAYAH, P., JOBST, E. E., TONELLI-LEMOS, L., BILLES, S. K., GLAVAS, M. M., GRAYSON, B. E., PERELLO, M. \& NILLNI, E. A. 2007. Diet-induced obesity causes severe but reversible leptin resistance in arcuate melanocortin neurons. Cell metabolism, 5, 181-194.

ESMAILIDEHAJ, M., KUCHAKZADE, F., REZVANI, M. E., FARHADI, Z., ESMAEILI, H. \& AZIZIAN, H. 2020. 17ß-Estradiol improves insulin signalling and insulin resistance in the aged female hearts: Role of inflammatory and anti-inflammatory cytokines. Life sciences, $253,117673$. 
FARHADI, Z., KHAKSARI, M., AZIZIAN, H., DABIRI, S., FALLAH, H. \& NOZARI, M. 2020. Aging is associated with loss of beneficial effects of estrogen on leptin responsiveness in mice fed high fat diet: Role of estrogen receptor a and cytokines. Mechanisms of ageing and development, 186, 111198.

FERNáNDEZ-AGULLó, T., ARRIBAS, C., ANDRES, A. \& CARRASCOSA, J. M. 2001. Decreased leptin uptake in hypothalamic nuclei with ageing in Wistar rats. Journal of Endocrinology, 171, 23-32.

FILIPPI, B. M. \& LAM, T. K. 2014. Leptin and aging. Aging (Albany NY), 6, 82.

FOSTER, T. C. 2012. Role of estrogen receptor alpha and beta expression and signaling on cognitive function during aging. Hippocampus, 22, 656-669.

GABRIELY, I., MA, X. H., YANG, X. M., ROSSETTI, L. \& BARZILAI, N. 2002. Leptin resistance during aging is independent of fat mass. Diabetes, 51, 1016-1021.

GAO, Q., MEZEI, G., NIE, Y., RAO, Y., CHOI, C. S., BECHMANN, I., LERANTH, C., TORAN-ALLERAND, D., PRIEST, C. A. \& ROBERTS, J. L. 2007. Anorectic estrogen mimics leptin's effect on the rewiring of melanocortin cells and Stat3 signaling in obese animals. Nature medicine, 13, 89-94.

HOSOI, T., OKUMA, Y., ONO, A. \& NOMURA, Y. 2005. Alteration of leptin-induced STAT3 activation in the brain of senescenceaccelerated mouse (SAM) P8. Biological and Pharmaceutical Bulletin, 28, 1514-1516.

KIMURA, M., IRAHARA, M., YASUI, T., SAITO, S., TEZUKA, M., YAMANO, S., KAMADA, M. \& AONO, T. 2002. The obesity in bilateral ovariectomized rats is related to a decrease in the expression of leptin receptors in the brain. Biochemical and biophysical research communications, 290, 1349-1353.

KOTZ, C. M., BILLINGTON, C. J. \& LEVINE, A. S. 1999. Obesity and aging. Clinics in geriatric medicine, 15, 391-412.

LEI, S., LIU, M., CHEN, X., DENG, F., LV, J., JIAN, W., XU, H., TAN, L., YANG, Y. \& WANG, Y. 2006. Relationship of total body fatness and five anthropometric indices in Chinese aged 20-40 years: different effects of age and gender. European journal of clinical nutrition, $60,511-518$.

LITWAK, S. A., WILSON, J. L., CHEN, W., GARCIA-RUDAZ, C., KHAKSARI, M., COWLEY, M. A. \& ENRIORI, P. J. 2014. Estradiol prevents fat accumulation and overcomes leptin resistance in female high-fat diet mice. Endocrinology, 155, 4447-4460.

LUDGERO-CORREIA JR, A., AGUILA, M. B., MANDARIM-DE-LACERDA, C. A. \& FARIA, T. S. 2012. Effects of high-fat diet on plasma lipids, adiposity, and inflammatory markers in ovariectomized C57BL/6 mice. Nutrition, 28, 316-323.

M CARRASCOSA, J., ANDRES, A., ROS, M., BOGONEZ, E., ARRIBAS, C., FERNANDEZ-AGULLO, T., J DE SOLIS, A., GALLARDO, N. \& MARTINEZ, C. 2011. Development of insulin resistance during aging: involvement of central processes and role of adipokines. Current Protein and Peptide Science, 12, 305-315.

MATYŠKOVá, R., ŽELEZNá, B., MAIXNEROVA, J., KOUTOVA, D., HALUZIK, M. \& MALETINSKA, L. 2010. Estradiol supplementation helps overcome central leptin resistance of ovariectomized mice on a high fat diet. Hormone and metabolic research, 42, $182-186$.

MAUVAIS-JARVIS, F., CLEGG, D. J. \& HEVENER, A. L. 2013. The role of estrogens in control of energy balance and glucose homeostasis. Endocrine reviews, 34, 309-338.

MILLER, C. N., BROWN, L. M., RAYALAM, S., DELLA-FERA, M. A. \& BAILE, C. A. 2012. Estrogens, inflammation and obesity: an overview. Frontiers in Biology, 7, 40-47.

MÜNZBERG, H., FLIER, J. S. \& BJøRBæK, C. 2004. Region-specific leptin resistance within the hypothalamus of diet-induced obese mice. Endocrinology, 145, 4880-4889.

PELLETIER, G., LI, S., LUU-THE, V. \& LABRIE, F. 2007. Oestrogenic regulation of pro-opiomelanocortin, neuropeptide Y and corticotrophin-releasing hormone mRNAs in mouse hypothalamus. Journal of neuroendocrinology, 19, 426-431.

Page $13 / 21$ 
ROSENBAUM, M., NICOLSON, M., HIRSCH, J., HEYMSFIELD, S. B., GALLAGHER, D., CHU, F. \& LEIBEL, R. L. 1996. Effects of gender, body composition, and menopause on plasma concentrations of leptin. The Journal of Clinical Endocrinology \& Metabolism, 81 , 3424-3427.

SCHWARTZ, M. W., PESKIND, E., RASKIND, M., BOYKO, E. J. \& PORTE, D. 1996. Cerebrospinal fluid leptin levels: relationship to plasma levels and to adiposity in humans. Nature medicine, 2, 589-593.

SCLAFANI, A. \& SPRINGER, D. 1976. Dietary obesity in adult rats: similarities to hypothalamic and human obesity syndromes. Physiology \& behavior, 17, 461-471.

TROEN, B. R. 2003. The biology of aging. The Mount Sinai journal of medicine, New York, 70, 3-22.

WOLDEN-HANSON, T., MARCK, B. T. \& MATSUMOTO, A. M. 2004. Blunted hypothalamic neuropeptide gene expression in response to fasting, but preservation of feeding responses to AgRP in aging male Brown Norway rats. American Journal of PhysiologyRegulatory, Integrative and Comparative Physiology, 287, R138-R146.

WU, Y., YU, Y., SZABO, A., HAN, M. \& HUANG, X.-F. 2014. Central inflammation and leptin resistance are attenuated by ginsenoside $\mathrm{Rb} 1$ treatment in obese mice fed a high-fat diet. PloS one, 9, e92618.

WYSOKIŃSKI, A., SOBóW, T., KŁOSZEWSKA, I. \& KOSTKA, T. 2015. Mechanisms of the anorexia of aging-a review. Age, 37, 1-14.

XU, Y., NEDUNGADI, T. P., ZHU, L., SOBHANI, N., IRANI, B. G., DAVIS, K. E., ZHANG, X., ZOU, F., GENT, L. M. \& HAHNER, L. D. 2011. Distinct hypothalamic neurons mediate estrogenic effects on energy homeostasis and reproduction. Cell metabolism, $14,453-465$.

YOKOSUKA, M., KALRA, P. S. \& KALRA, S. P. 1999. Inhibition of neuropeptide Y (NPY)-induced feeding and c-Fos response in magnocellular paraventricular nucleus by a NPY receptor antagonist: a site of NPY action. Endocrinology, 140, 4494-4500.

\section{Figures}

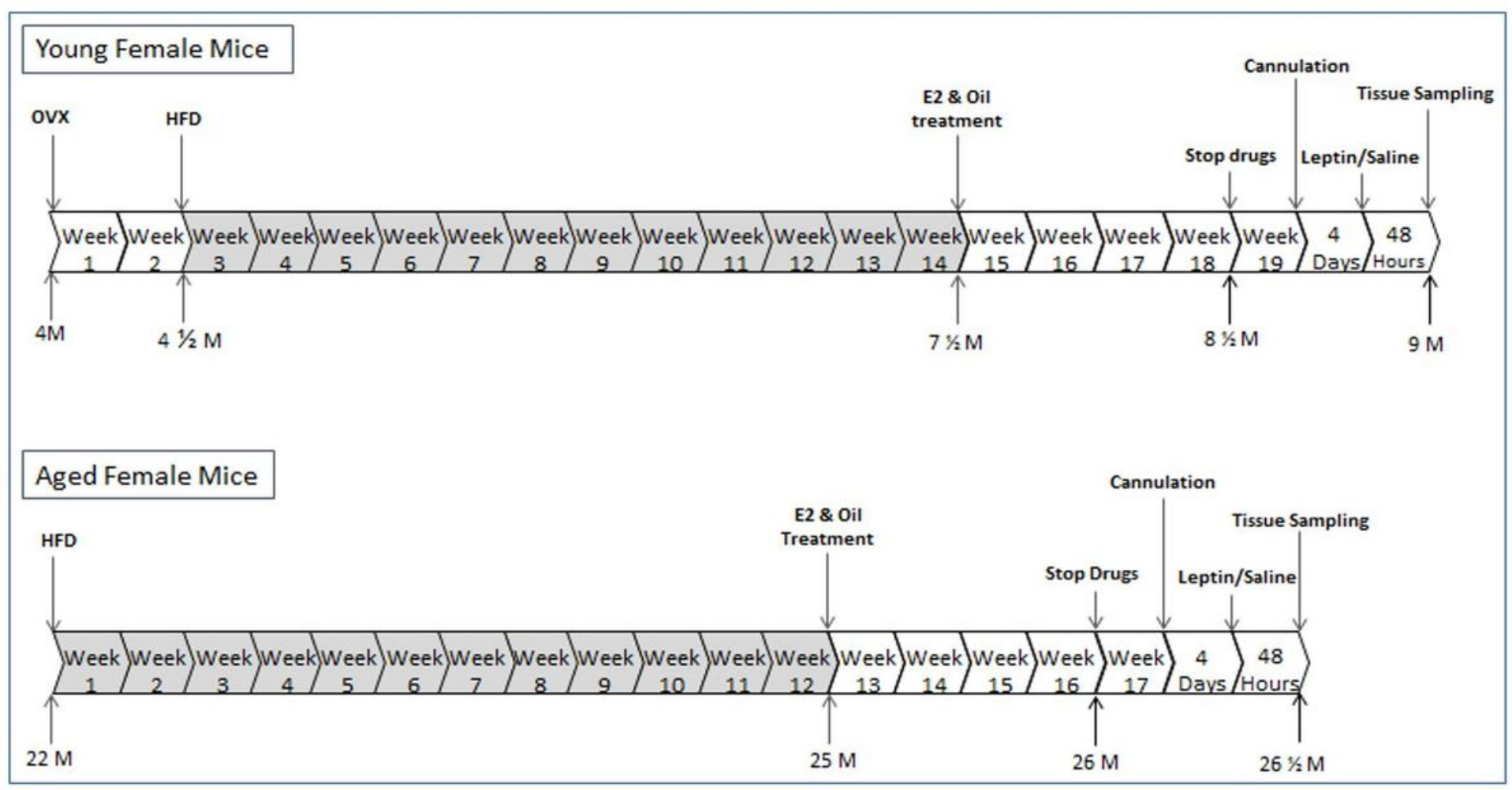

Figure 1 
A schematic diagram of the study design and treatment schedule. E2: 17- $\beta$ Estradiol, HFD: High fat diet, M: Months, OVX: Ovariectomy.

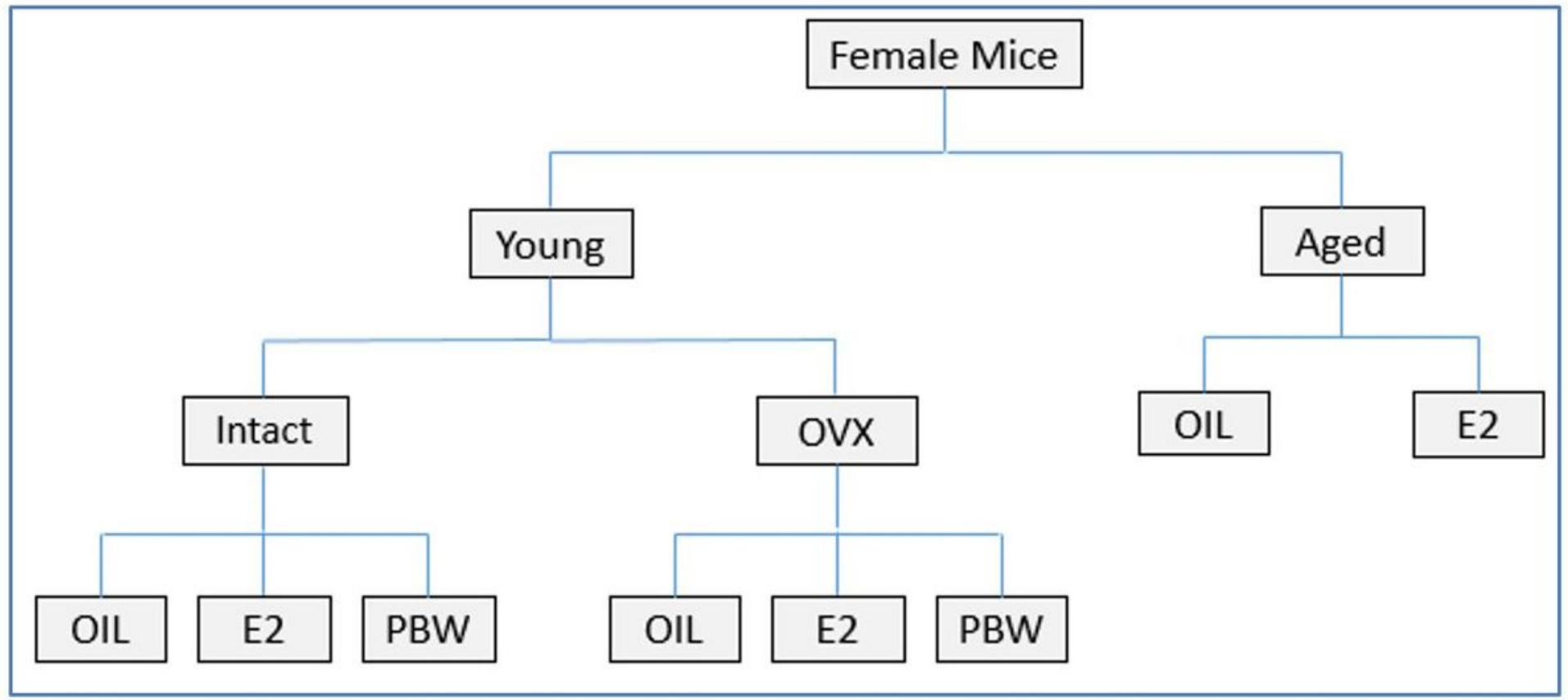

Figure 2

A schematic representation of experimental group. OVX: Ovariectomy, E2: 17- $\beta$ Estradiol, PBW: Pair body weight. 

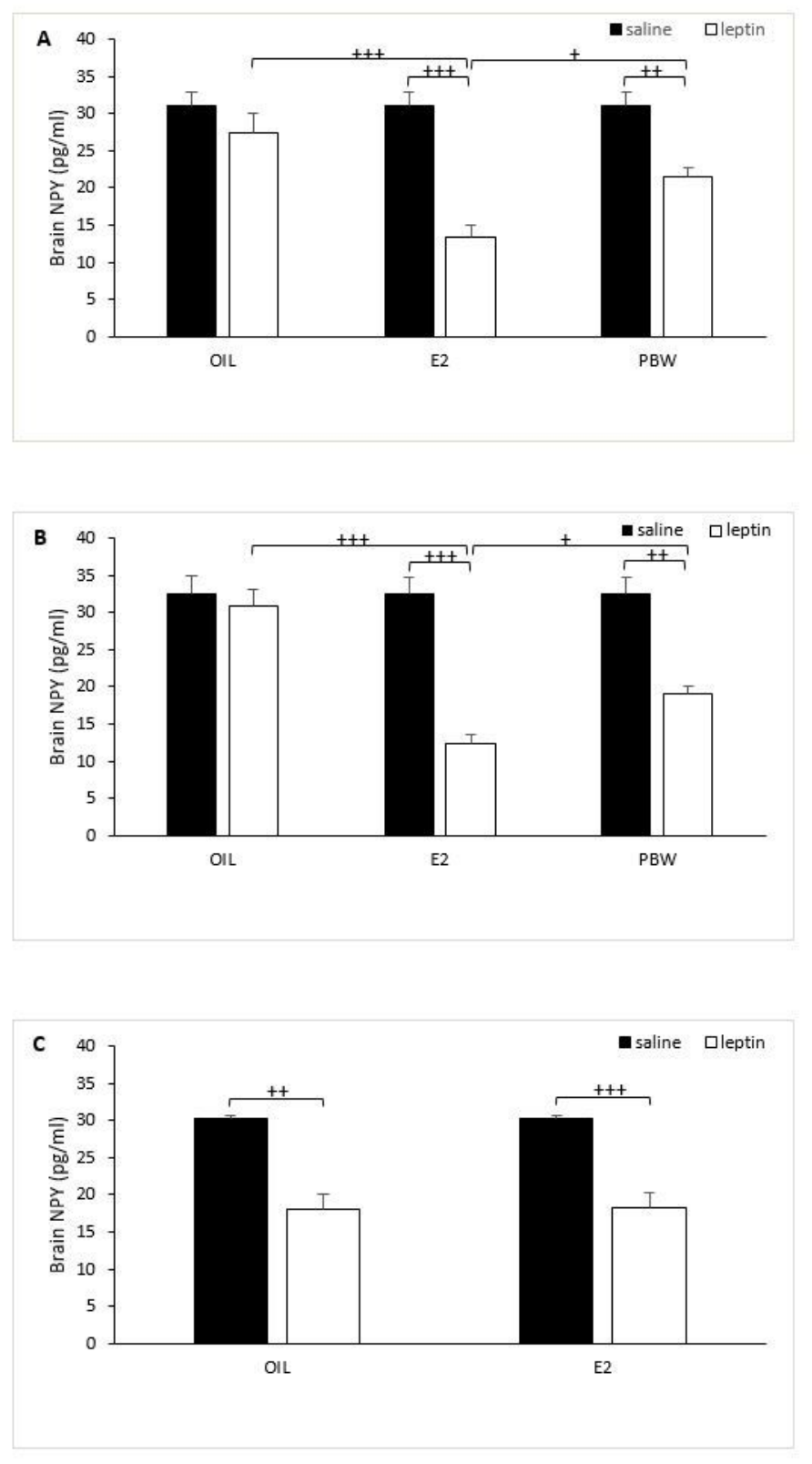

\section{Figure 3}

The effect of central leptin $(0.2 \mu \mathrm{g} / \mu \mathrm{l})$ injection on brain NPY in HFD fed mice treated by E2 or oil during $48 \mathrm{~h}$ after a single injection of leptin compared with saline. Brain levels of NPY in A: young intact, B: young OVX, and C: Aged animals were fed by HFD. Results are expressed as mean \pm SEM., $n=8$ /group. $+P<0.05,++P<0.01$, and $+++P<0.001$. E2: 17- $\beta$ Estradiol, NPY: Neuropeptide $Y, P B W$ : Pair body weight. 

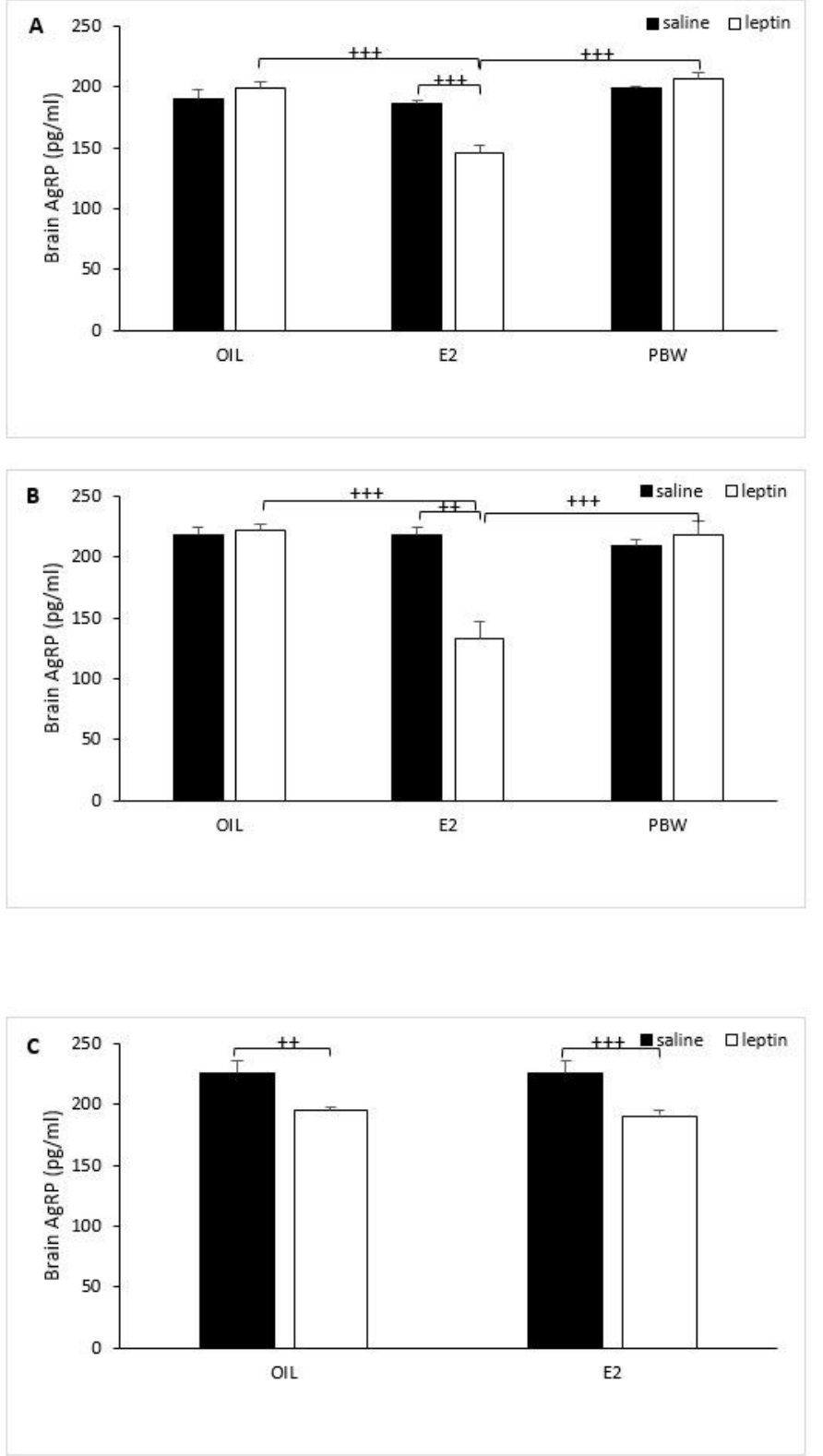

Figure 4

The effect of central leptin $(0.2 \mu \mathrm{g} / \mu \mathrm{l})$ injection on brain AgRP in HFD fed mice treated by E2 and oil during $48 \mathrm{~h}$ after a single injection of leptin compared with saline. Brain levels of AgRP in A: young intact, B: young OVX, C: Aged animals were fed by HFD. Results are expressed as mean \pm SEM., $n=8$ /group. $++P<0.01$ and $+++P<0.001$. E2: 17- $\beta$ Estradiol, AgRP: Agouti-Related Peptide, PBW: Pair body weight. 

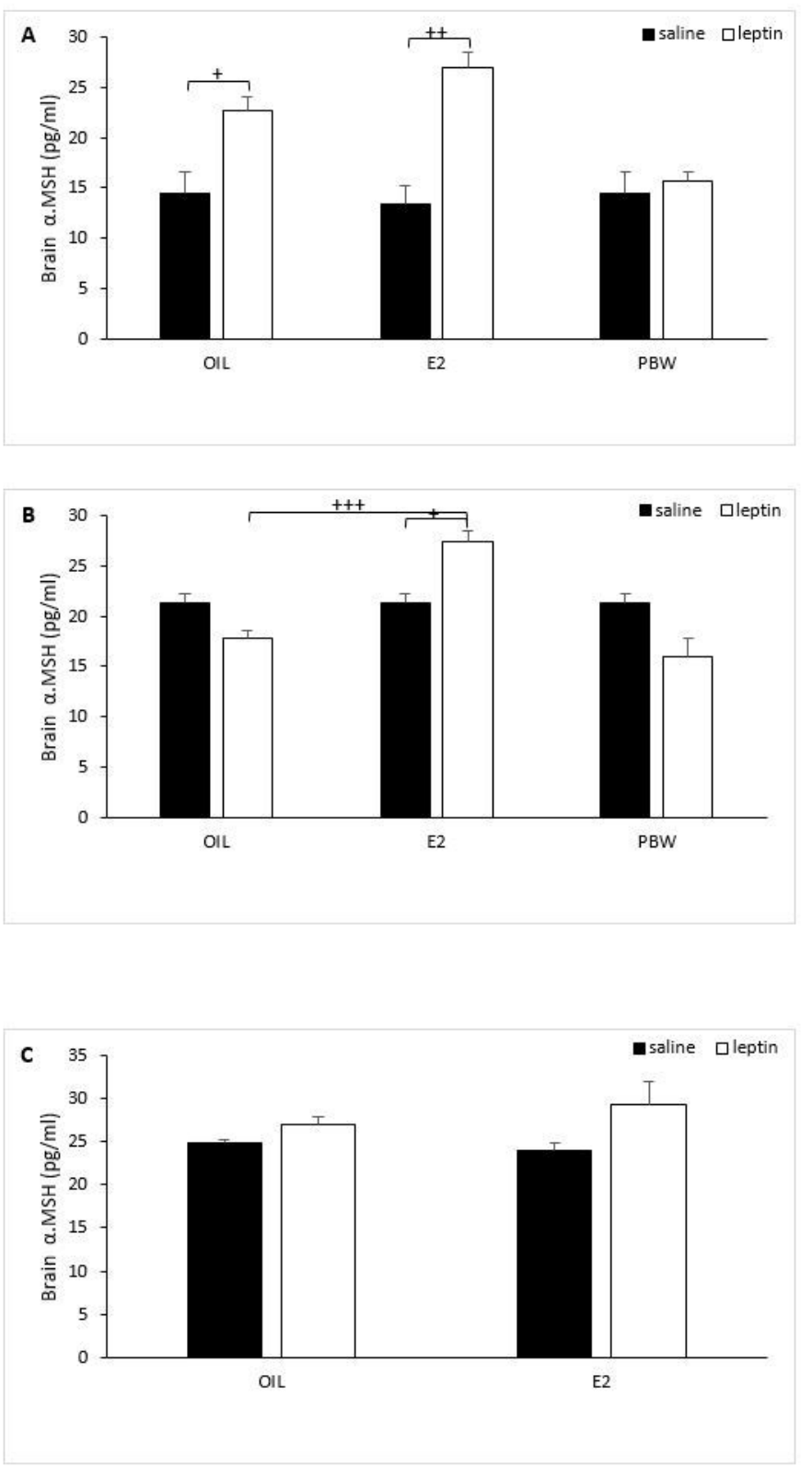

\section{Figure 5}

The effect of central leptin $(0.2 \mu \mathrm{g} / \mu \mathrm{l})$ injection on brain a-MSH in HFD fed mice treated by E2 and oil during $48 \mathrm{~h}$ after a single injection of leptin compared with saline. Brain levels of a-MSH in A: young intact, B: young OVX, C: Aged animals were fed by HFD. Results are expressed as mean \pm SEM., $n=8$ /group. $+P<0.05,++P<0.01$, and $+++P<0.001$. E2: $17-\beta$ Estradiol, $a-M S H: a-$ Melanocyte-stimulating hormone, PBW: Pair body weight. 


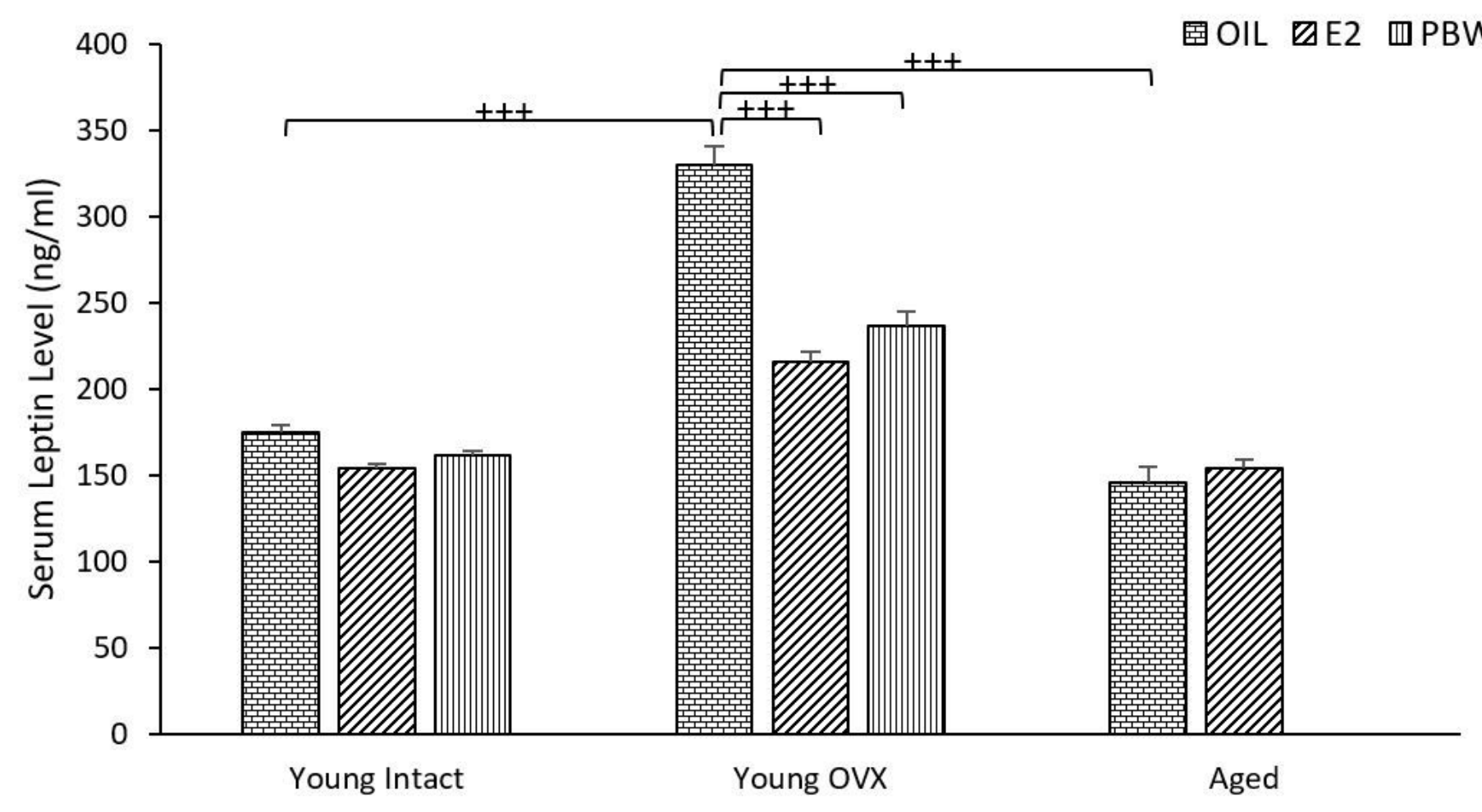

Figure 6

Changes of serum level of leptin $(\mathrm{ng} / \mathrm{ml})$ in young intact, OVX, and aged animals fed mice treated by E2 and oil. Results are expressed as mean \pm SEM., $n=8 /$ group. $+++P<0.001$. E2: 17- $\beta$ estradiol, OVX: Ovariectomy, PBW: Pair body weight. 


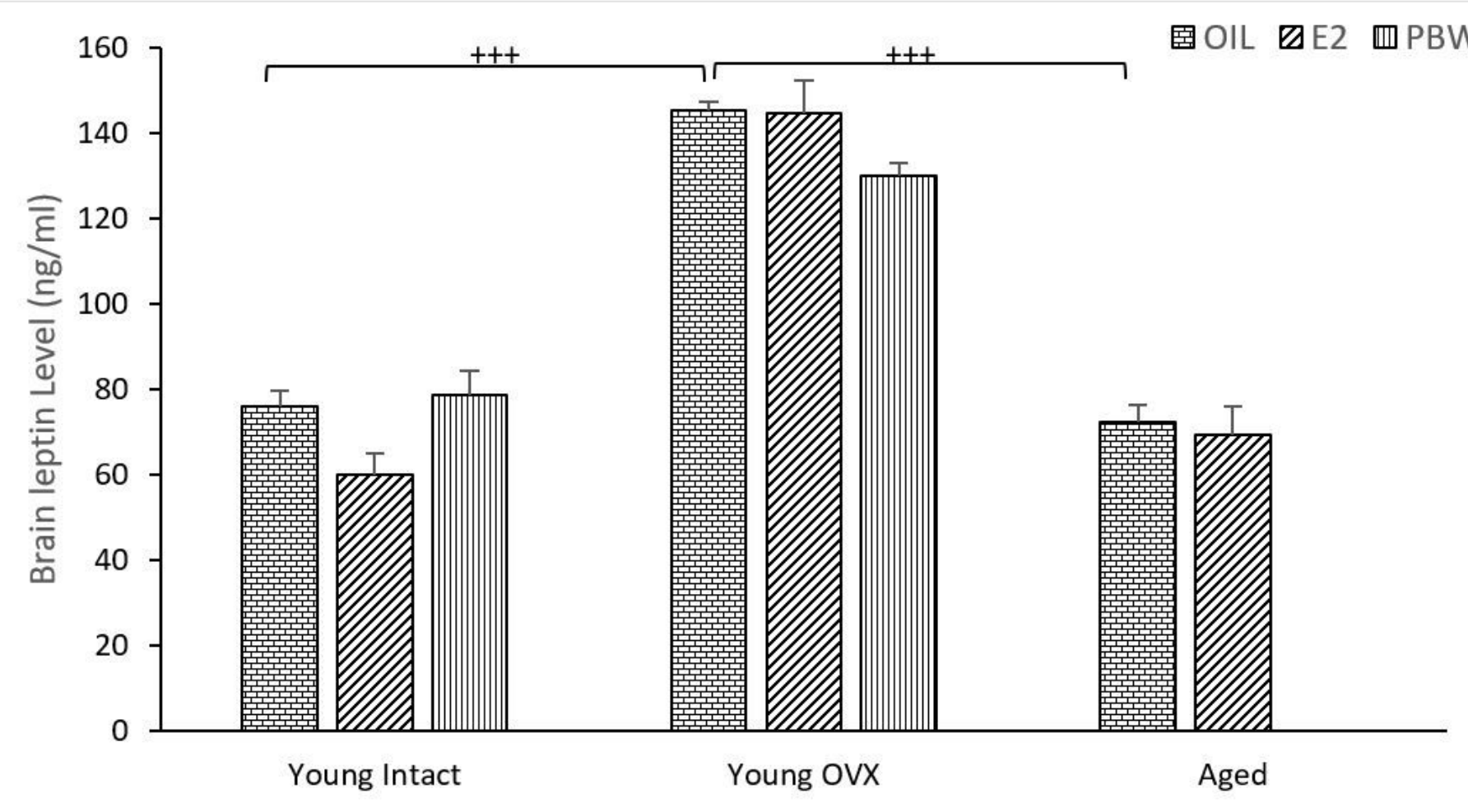

Figure 7

Changes of brain level of leptin $(\mathrm{ng} / \mathrm{ml})$ in young intact, OVX, and aged animals fed mice treated by E2 and oil. Results are expressed as mean \pm SEM., $n=8$ /group. $+++P<0.001$. E2: 17- $\beta$ Estradiol, OVX: Ovariectomy, PBW: Pair body weight. 


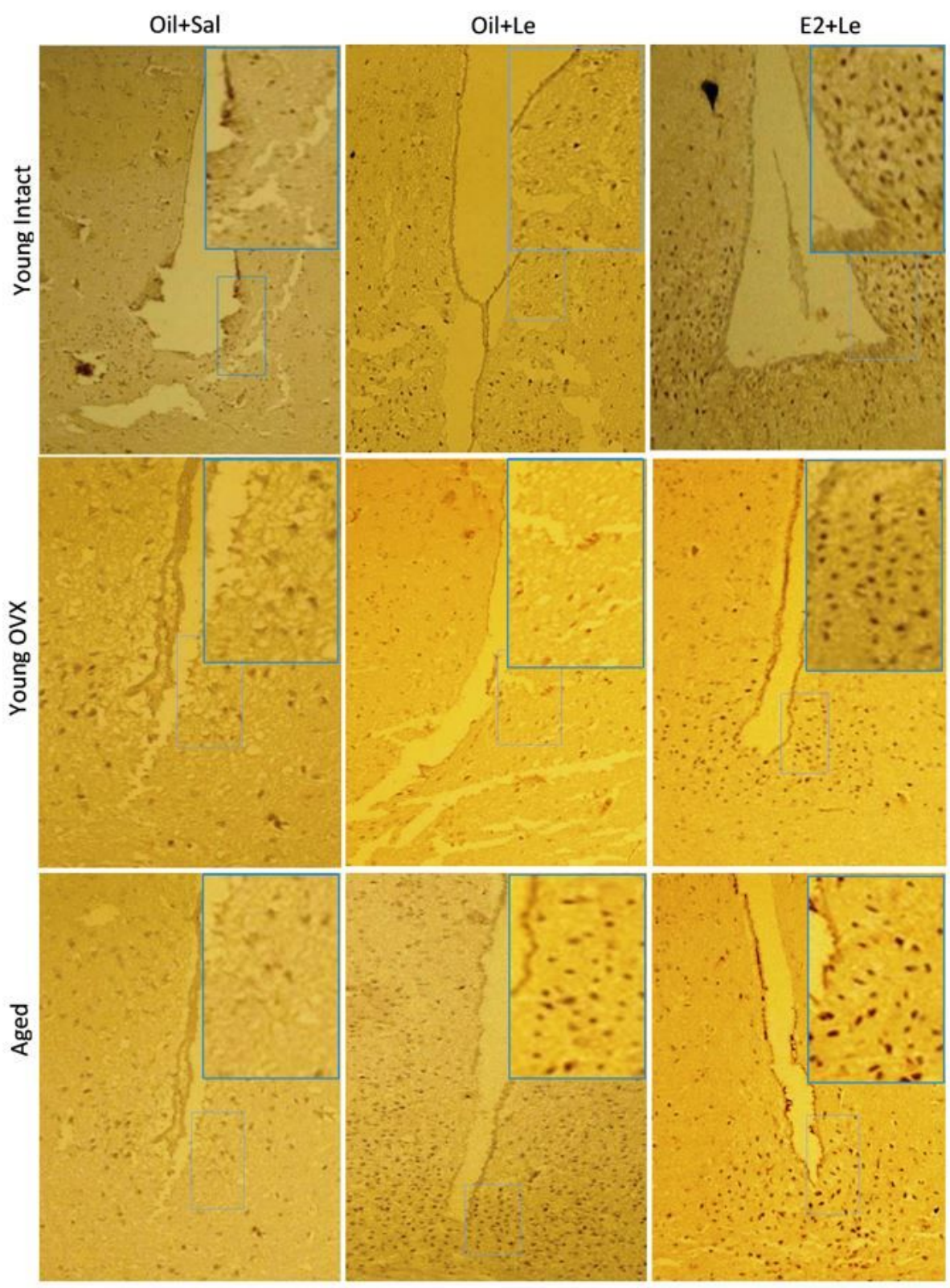

\section{Figure 8}

Representative microscopic IHC sections of p-STAT3-positive cell number in arcuate nucleus of the hypothalamus in HFD fed mice treated by E2 and oil. E2: 17- $\beta$ Estradiol, Lep: Leptin, OVX: Ovariectomy, Sal: Salin. 